University of Wollongong

Research Online

Faculty of Engineering and Information

Faculty of Engineering and Information

Sciences - Papers: Part A

Sciences

$1-1-2014$

Observations on the zirconium hydride precipitation and distribution in Zircaloy-4

Zhiyang Wang

University of Wollongong, zw603@uowmail.edu.au

Ulf Garbe

ANSTO

Huijun Li

University of Wollongong, huijun@uow.edu.au

Robert P. Harrison

ANSTO

Anders Kaestner

Paul Scherrer Institute

See next page for additional authors

Follow this and additional works at: https://ro.uow.edu.au/eispapers

Part of the Engineering Commons, and the Science and Technology Studies Commons

Research Online is the open access institutional repository for the University of Wollongong. For further information contact the UOW Library: research-pubs@uow.edu.au 


\title{
Observations on the zirconium hydride precipitation and distribution in Zircaloy-4
}

\begin{abstract}
Hydride precipitation and distribution in hot-rolled and annealed Zircaloy-4 plate samples artificially induced by gaseous hydrogen charging were studied primarily by neutron tomography, scanning electron microscopy (SEM), and SEM-based electron backscattered diffraction techniques. The precipitated hydride platelet ( $\delta-\mathrm{ZrH} 1.66)$ at a hydrogen pressure of 20 atm was found following the $\{111\} \delta$ $\mathrm{ZrH} 1.66 / /(0001) \alpha-\mathrm{Zr}$ with the surrounding $\alpha-\mathrm{Zr}$ matrix. The microstructural characterization indicated that hydrides with a relatively uniform distribution were precipitated on the rolling-transverse section of the plate, whereas, on the normal-transverse section, a hydride concentration gradient was present with a dense hydride layer near the surface. Further, the neutron tomography investigations clearly identified the nonuniform spatial distribution of hydrides. Thin hydride layers preferentially formed on the sample surface, and the concentrated hydrides precipitating at the edges/corner of the sample were observed. The causes for the localized hydride accumulation were also discussed.

Disciplines

Engineering | Science and Technology Studies

Publication Details

Wang, Z., Garbe, U., Li, H., Harrison, R. P., Kaestner, A. \& Lehmann, E. (2014). Observations on the zirconium hydride precipitation and distribution in Zircaloy-4. Metallurgical and Materials Transactions B: Process Metallurgy and Materials Processing Science, 45 (2), 532-539.
\end{abstract}

\section{Authors}

Zhiyang Wang, Ulf Garbe, Huijun Li, Robert P. Harrison, Anders Kaestner, and Eberhard Lehmann 


\title{
Observations on the Zirconium Hydride Precipitation and Distribution in Zircaloy-4
}

\author{
ZHIYANG WANG, ULF GARBE, HUIJUN LI, ROBERT P. HARRISON, \\ ANDERS KAESTNER, and EBERHARD LEHMANN
}

\begin{abstract}
Hydride precipitation and distribution in hot-rolled and annealed Zircaloy-4 plate samples artificially induced by gaseous hydrogen charging were studied primarily by neutron tomography, scanning electron microscopy (SEM), and SEM-based electron backscattered diffraction techniques. The precipitated hydride platelet $\left(\delta-\mathrm{ZrH}_{1.66}\right)$ at a hydrogen pressure of $20 \mathrm{~atm}$ was found following the $\{111\}_{\delta \text {-ZrH1.66 }} / /(0001)_{\alpha-\mathrm{Zr}}$ with the surrounding $\alpha-\mathrm{Zr}$ matrix. The microstructural characterization indicated that hydrides with a relatively uniform distribution were precipitated on the rolling-transverse section of the plate, whereas, on the normal-transverse section, a hydride concentration gradient was present with a dense hydride layer near the surface. Further, the neutron tomography investigations clearly identified the nonuniform spatial distribution of hydrides. Thin hydride layers preferentially formed on the sample surface, and the concentrated hydrides precipitating at the edges/ corner of the sample were observed. The causes for the localized hydride accumulation were also discussed.
\end{abstract}

DOI: $10.1007 / \mathrm{s} 11663-013-9866-0$

(C) The Minerals, Metals \& Materials Society and ASM International 2013

\section{INTRODUCTION}

THE zirconium alloy, Zircaloy-4 (Zr-4), is used extensively in nuclear reactors as a key structural material (for example, as a fuel cladding material or for research reactor reflector vessels) because of its attractive combination of low neutron absorption cross section, good corrosion resistance, and excellent mechanical properties. ${ }^{[1,2]}$ However, formation of brittle hydrides in Zr-4 during service will result in a decreased ductility and fracture toughness of the material. Moreover, some $\mathrm{Zr}-4$ components are susceptible to a crack initiation and propagation process called delayed hydride cracking (DHC), potentially reducing their usable lifetime. ${ }^{[3,4]}$ Hydride formation is a complicated process, influenced by several factors including the microstructure and texture of $\mathrm{Zr}-4$, applied or residual stresses, and temperature gradients. ${ }^{[4,5]}$ So far, research

\footnotetext{
ZHIYANG WANG, Ph.D. Candidate, is with Faculty of Engineering, University of Wollongong, Northfields Avenue, Wollongong, NSW 2522, Australia, and also with The Bragg Institute, Australian Nuclear Science and Technology Organisation (ANSTO), New Illawarra Road, Lucas Heights, NSW 2234, Australia. Contact e-mail: zw603@uowmail.edu.au ULF GARBE, Instrument Scientist, is with The Bragg Institute, Australian Nuclear Science and Technology Organisation (ANSTO). HUIJUN LI, Associate Professor, is with Faculty of Engineering, University of Wollongong. ROBERT P. HARRISON, Program Leader, is with The Institute of Materials Engineering, Australian Nuclear Science and Technology Organisation, Lucas Heights, NSW. ANDERS KAESTNER, Beamline Scientist, and EBERHARD LEHMANN, Group Leader, are with Paul Scherrer Institut (PSI), 5232, Villigen PSI, Switzerland.

Manuscript submitted January 17, 2013.

Article published online May 14, 2013.
}

on the precipitation and distribution of hydrides in $\mathrm{Zr}-4$ acting as a fracture initiator has received considerable attention. ${ }^{[5,6]}$

Observation of hydride formation in $\mathrm{Zr}-4$ alloys has been conducted via various techniques such as X-ray diffraction, optical or electron microscopy, and electron backscattered diffraction (EBSD). ${ }^{[1,2,4]}$ Sufficient information in terms of the phase, morphology, and size of hydrides, and the orientation relationship between the hydride and matrix phases can be derived from these investigations. For example, the thin platelet morphology of $\delta$-hydride $\left(\mathrm{ZrH}_{1.66}\right)$, the most common hydride phase in practical reactor conditions, has been directly observed through the destruction metallographic examination using optical or scanning electron microscopy (SEM) ${ }^{[7]}$ Nevertheless, owing to the restricted areas of detection, the hydride distribution on the macroscopic or spatial scales cannot be well examined by the approaches above. Neutron tomography, as a nondestructive tool for materials testing, enables the inspection of bulk samples containing low-atomic-number elements (especially hydrogen) beneath the matrixes. This technique has been used to investigate the formation of hydride blisters ${ }^{[8]}$ and hydrogen concentration ${ }^{[9-11]}$ in zirconium alloys. The characterization using neutron tomography and other metallographic detection methods could essentially provide an overall description of the spatial distribution and microstructural features of hydrides. In the current study, neutron tomography together with SEM and EBSD approaches were primarily applied to characterize the hydride-formation behaviors induced by gaseous hydrogen charging in $\mathrm{Zr}$ 4 plate samples, with the special emphasis on revealing the distribution features of hydrides. 


\section{EXPERIMENTAL PROCEDURE}

\section{A. Samples}

Hot-rolled and annealed $\mathrm{Zr}-4$ plate samples with a chemical composition of $\mathrm{Zr}_{98.11} \mathrm{Sn}_{1.56} \mathrm{Fe}_{0.22} \mathrm{Cr}_{0.11} \mathrm{O}_{0.14}$ (wt pct) were used in the current study. The samples for hydrogenation had irregular shapes and a maximum length of $\sim 12 \mathrm{~mm}$. The samples were first immersed in an acid solution of $10 \mathrm{~mL} \mathrm{HF}, 45 \mathrm{~mL} \mathrm{HNO}_{3}$, and $10 \mathrm{~mL}$ distilled water for 2 minutes to remove the native oxide layer present on the surface, and then gaseously hydrided in a Sieverts apparatus (Advanced Materials Corporation) using high purity hydrogen (99.9 pct) at pressures of 10 and $20 \mathrm{~atm}$. Three identical thermal cycling processes were conducted to prepare the hydrided samples. For each thermal cycle, the samples were soaked at a temperature of $723 \mathrm{~K}\left(450{ }^{\circ} \mathrm{C}\right)$ for 5 hours, followed by furnace cooling with a cooling rate of $\sim 275.3 \mathrm{~K}\left(\sim 2.2^{\circ} \mathrm{C}\right)$ per minute.

\section{B. Characterization}

The phases of the as-received and hydrided $\mathrm{Zr}-4$ samples were identified by a GBC MMA X-ray diffractometer (XRD) with $\mathrm{Cu} \mathrm{K} \alpha$ radiation $(\lambda=0.15418 \mathrm{~nm})$ at $28.6 \mathrm{~mA}$ and $35 \mathrm{kV}$, using a continuous-scan mode. A quick scan of $4 \mathrm{deg} / \mathrm{min}$ was initially performed over a wide range of $2 \theta=30$ to 110 deg for all samples. A slower scan rate of $1 \mathrm{deg} / \mathrm{min}$ was further used over $2 \theta=31$ to $34 \mathrm{deg}$ and 63 to $66 \mathrm{deg}$ to insure a more accurate determination of the diffraction peaks. Samples for metallographic examinations were cut, mounted in epoxy casts, and then mechanically polished to 1200 grit silicon carbide paper, followed by chemical etching using a solution consisting of $10 \mathrm{~mL} H F, 100 \mathrm{~mL}$ $\mathrm{HNO}_{3}$, and $100 \mathrm{~mL}$ distilled water for 30 seconds. Microstructures of the hydrided and the unhydrided samples were characterized using a JEOL JSM-6490LA SEM at an accelerating voltage of $20 \mathrm{kV}$. The EBSD observation was also conducted on the 20 -atm-hydrided sample using a Zeiss Ultra Plus field emission gun SEM equipped with an Oxford/HKL system operating at $30 \mathrm{kV}$. The sample for EBSD analysis was prepared by electrolytic polishing applying an electrolyte consisting of 95 pet $\mathrm{CH}_{3} \mathrm{OH}$ and 5 pet $\mathrm{HClO}_{4}$ at $30 \mathrm{~V} \mathrm{DC}$ and at $298 \mathrm{~K}\left(25^{\circ} \mathrm{C}\right)$. The Vickers microhardness was determined using a LECO M-400-H1 microhardness tester at a load of $0.3 \mathrm{~kg}$ and an indentation dwelling time of 12 seconds. An average of 12 indents was taken for each sample.

The neutron tomography investigations on a selected sample hydrided at $20 \mathrm{~atm}$ were conducted at the ICON beamline (SINQ, PSI Villigen, Switzerland) using the micro-tomography setup. ${ }^{[12]}$ The sample stage used for this experiment consists of a motorized positioning system and a turn-table allowing the tomographic imaging in the range of $360 \mathrm{deg}$. A detector system based on a combination of a scintillator screen and a CCD-camera was applied to acquire the images for tomography. During the tomographic imaging, the sample was rotated about its axis at a given angular step of 0.3 deg and radiographic projections were taken for each rotation step. These radiographs were then reconstructed to obtain the $3 \mathrm{D}$ tomographic images of the sample using the reconstruction software Octopus 8.5 and the visualization tool VGStudio MAX 2.1 package.

\section{RESULTS AND DISCUSSION}

\section{A. Phase Identification and Quantification}

Typical XRD patterns of the as-received and the hydrided $\mathrm{Zr}-4$ samples at different hydrogen pressures are shown in Figure 1. Clearly, a single hexagonal-closepacked (hcp) $\alpha-\mathrm{Zr}$ (JCPDS Card No. 05-0665) was detected in the as-received sample. When hydriding at hydrogen pressures of 10 and $20 \mathrm{~atm}$, face-centeredcubic (fcc) $\delta-\mathrm{ZrH}_{1.66}$ (JCPDS Card No. 34-0649) and $\alpha-\mathrm{Zr}$ were identified. The diffraction peaks of $\delta-\mathrm{ZrH}_{1.66}$ became more intense in the 20 -atm-hydrided sample than that of the 10-atm-hydrided sample. Furthermore, with the hydriding pressure rising from 10 to $20 \mathrm{~atm}$, the peak intensity ratios $I_{\delta(111)} / I_{\alpha(10 \overline{1}))}$ and $I_{\delta(200)} / I_{\alpha(10 \overline{1} 1)}$ increased significantly, from 2.34 to 15.1 , and from 0.04 to 0.46 , respectively, indicating an increase in the volume fraction of the formed $\delta$-hydride at a higher hydrogen pressure. A semi-quantitative phase analysis for the $\delta$-hydride volume fractions and hydrogen contents was also performed by comparing the integrated intensities of the $\delta$-hydride and $\alpha$-Zr peaks using the procedure and weighting factors described in literature. ${ }^{[13]}$ The volume ratio of $\delta-\mathrm{ZrH}_{1.66}$ and $\alpha-\mathrm{Zr}$ phases can be estimated according to the following equation ${ }^{[14]}$ :

$$
\begin{aligned}
\frac{V_{\delta}}{V_{\alpha}}= & \frac{I_{\delta(111)}}{I_{\alpha(0002)}} \times \frac{R_{\alpha(0002)}}{R_{\delta(111)}}=\frac{I_{\delta(111)}}{I_{\alpha(0002)}} \\
& \times \frac{\left[\frac{1}{v^{2}} P\left|F_{\mathrm{hkl}}\right|^{2}\left(\frac{1+\cos ^{2} 2 \theta}{\sin ^{2} \theta \cos \theta}\right) e^{-2 M}\right]_{\alpha(0002)}}{\left[\frac{1}{v^{2}} P\left|F_{\mathrm{hk} 1}\right|^{2}\left(\frac{1+\cos ^{2} 2 \theta}{\sin ^{2} \theta \cos \theta}\right) e^{-2 M}\right]_{\delta(111)}}
\end{aligned}
$$

where, for a specific peak, $v$ is the unit cell volume $\left(\mathrm{m}^{3}\right), F_{\mathrm{hkl}}$ is the structure factor of the lattice cell, $P$ is the multiplicity factor, $\left(1+\cos ^{2} 2 \theta\right) /\left(\sin ^{2} \theta \cos \theta\right)$ is the angle factor, and $M$ is a parameter related to the average displacement of an atom from its mean position. For the hydrided samples processed at 10 and $20 \mathrm{~atm}$, the ratios of the intensity of the strongest diffraction peaks of $\delta-\mathrm{ZrH}_{1.66}$ (111) and $\alpha-\mathrm{Zr}(0002)$, $I_{\delta(111)} / I_{\alpha(0002)}$, were 0.1 and 0.9 , respectively. The volume fractions $V_{\delta}$ of the $\delta$-hydride phase in the 10- and 20-atm-hydrided samples can thus be calculated to be 1 and 10 pct, respectively. From the calculation results of $V_{\delta}$, the corresponding hydrogen contents [H] were then estimated to be 182 and $1584 \mathrm{ppm}$, respectively, using the following equation ${ }^{[13]}$ :

$$
[\mathrm{H}]=[\mathrm{H}]_{\delta} \cdot V_{\delta} \cdot\left[\frac{\rho_{\delta}}{\rho_{\alpha-\mathrm{Zr}} \cdot\left(1-V_{\delta}\right)+\rho_{\delta} \cdot V_{\delta}}\right]
$$

where $[\mathrm{H}]_{\delta}$ is the hydrogen content of $\delta-\mathrm{ZrH}_{1.66}$ phase, $\rho_{\delta}$ is the density of $\delta$-hydride at room temperature 
$\left(\sim 5.65 \mathrm{~g} / \mathrm{cm}^{3}\right)$, and $\rho_{\alpha-\mathrm{Zr}}$ is the density of $\alpha-\mathrm{Zr}$ at room temperature $\left(\sim 6.51 \mathrm{~g} / \mathrm{cm}^{3}\right)$. It should be pointed out that, owing to the limited penetration depth of the laboratory X-ray $\mathrm{Cu} \mathrm{K} \alpha$ radiation in the hydrided $\mathrm{Zr}-4$ samples $(\sim 10 \mu \mathrm{m}),{ }^{[15]}$ the XRD analysis results only represented the semi-quantitative information of the average hydride/hydrogen contents in the irradiated surface regions.

Figure 2 depicts a further fine scan result for the diffraction peaks of the hydrided samples in the vicinity of the standard $\delta-\mathrm{ZrH}_{1.66}$ hydride peaks. In general, the identified $\delta$-hydride peaks shifted toward higher Bragg angles. This displacement is probably caused by the expected compressive stress from hydride precipitation because of the constraint of $\alpha$-Zr grains, ${ }^{[13]}$ as there is an appreciable volume expansion of 17.2 pct for $\delta$-hydride compared to the $\alpha-\mathrm{Zr}$ matrix. ${ }^{[16]}$ Such compressive stress within hydrides has already been manifested by the recent synchrotron X-ray diffraction experiments. ${ }^{[17]}$ Moreover, at a relatively low hydriding pressure of $10 \mathrm{~atm}$, the positions of the $\delta$-hydride peaks shifted slightly toward higher $2 \theta$ in comparison with those of the standard hydride peaks, with the $\delta(111)$ peak shifted by $\approx 0.048 \mathrm{deg}$ and $\delta(311)$ peak by $\approx 0.057 \mathrm{deg}$. When the hydriding pressure was increased to $20 \mathrm{~atm}$, a marked shift for the positions of the $\delta$-hydride peaks reaching 0.36 to $0.48 \mathrm{deg}$ in the higher $2 \theta$ direction was visible. As the volume fraction of the hydrides formed increases with the increasing hydrogen pressure, a larger compressive stress in the hydrides is induced. Thus, a significant displacement of hydride peak locations would occur, and this was observed in the hydrided sample at 20 atm (Figure 2).

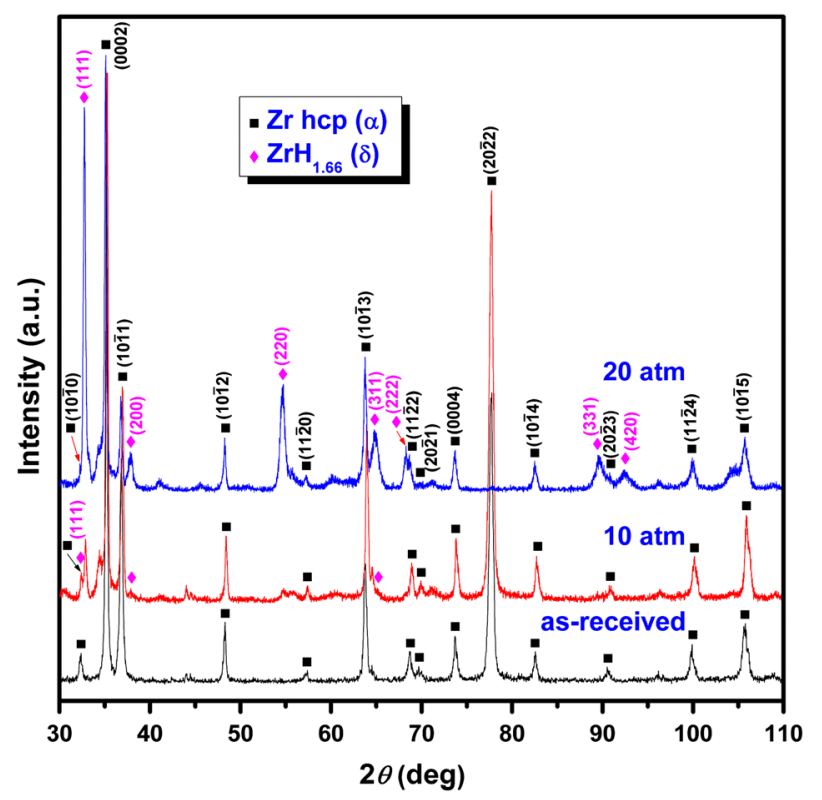

Fig. 1-XRD patterns of the as-received and the hydrided $\mathrm{Zr}-4$ samples under hydrogen pressures of 10 and 20 atm (JCPDS Card Nos. $\alpha-\mathrm{Zr}$ : 05-0665; $\delta-\mathrm{ZrH}_{1.66}$ : 34-0649).

\section{B. Microstructure, Microhardness, and Microtexture Characterization}

Figures 3(a) through (c) present the characteristic microstructures on RD-TD (rolling direction-transverse direction) sections of the as-received and the hydrided $\mathrm{Zr}-4$ samples. The as-received matrix had equiaxed grains, while the microstructures of the hydrided samples showed a mixture of equiaxed grains and platelet-shaped hydrides. Hydride platelets were observed to generally align along the RD direction in RDTD planes, consistent with the results given by Kiran Kumar et al..$^{[1]}$ and Oh et al. ${ }^{[18]}$ Further, it was found that a higher volume fraction of hydrides together with longer hydride platelets formed in the 20-atm-hydrided $\mathrm{Zr}-4$ in contrast to that in the 10-atm-hydrided sample (Figures 3(b) and (c)). As revealed in our previous study, ${ }^{[19,20]}$ a higher hydrogen absorption at the elevated hydriding pressure is yielded, favoring the growth of hydride platelets and resulting in the precipitation of a larger amount of hydrides. The Vickers microhardness values for the matrix and the hydrided samples are also shown in Figure 3(d). The microhardness was measured on the RD-TD sections in 12 different positions, and the reported microhardness is the average of these measurements. As expected, the microhardness increases with increasing the hydride volume fraction (i.e., increasing the hydriding pressure). The microhardness of the $\mathrm{Zr}-4$ matrix was $205 \mathrm{HV}_{0.3}$, which increased to $224 \mathrm{HV}_{0.3}$ for the sample hydrided at $10 \mathrm{~atm}$. For the sample hydrided at $20 \mathrm{~atm}$, the microhardness was further elevated to 244 $\mathrm{HV}_{0.3}$. This increase in the microhardness is ascribed to the matrix hardening effect induced by hydrides that are embedded in the Zr-4 matrix. ${ }^{[21]}$ Besides, the considerably inhomogeneous hydride distribution in the 10-atmhydrided sample (Figure 3(b)) resulted in a significant fluctuation of microhardness (as reflected by the large error bar). In contrast, a relatively uniform distribution of the microhardness was achieved in the 20-atmhydrided sample on the RD-TD section because of the formation of homogenously dispersed hydrides (Figure 3(c)).

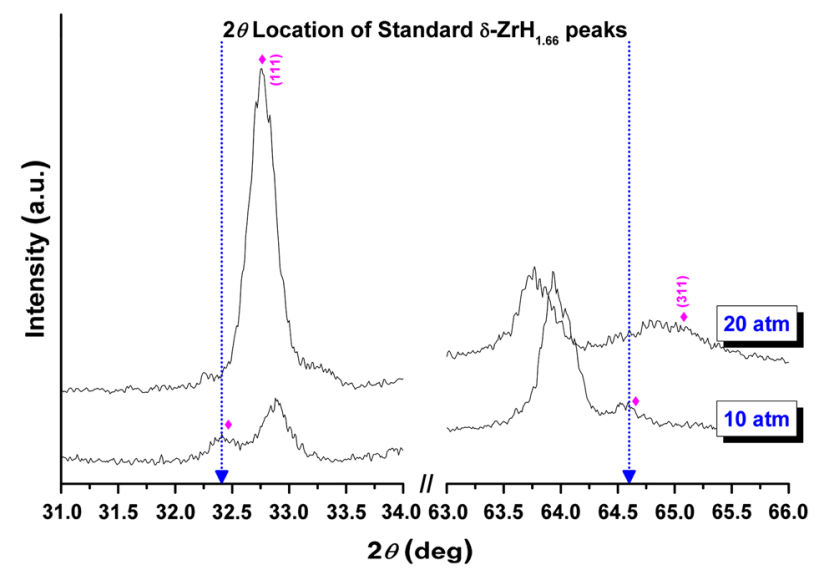

Fig. 2-XRD patterns in the vicinity of 31 to 34 and 63 to $66 \mathrm{deg}$ $(2 \theta)$, showing the shift in $2 \theta$ positions of the $\delta$-hydride peaks compared with the standard $\delta$-hydride peaks. 

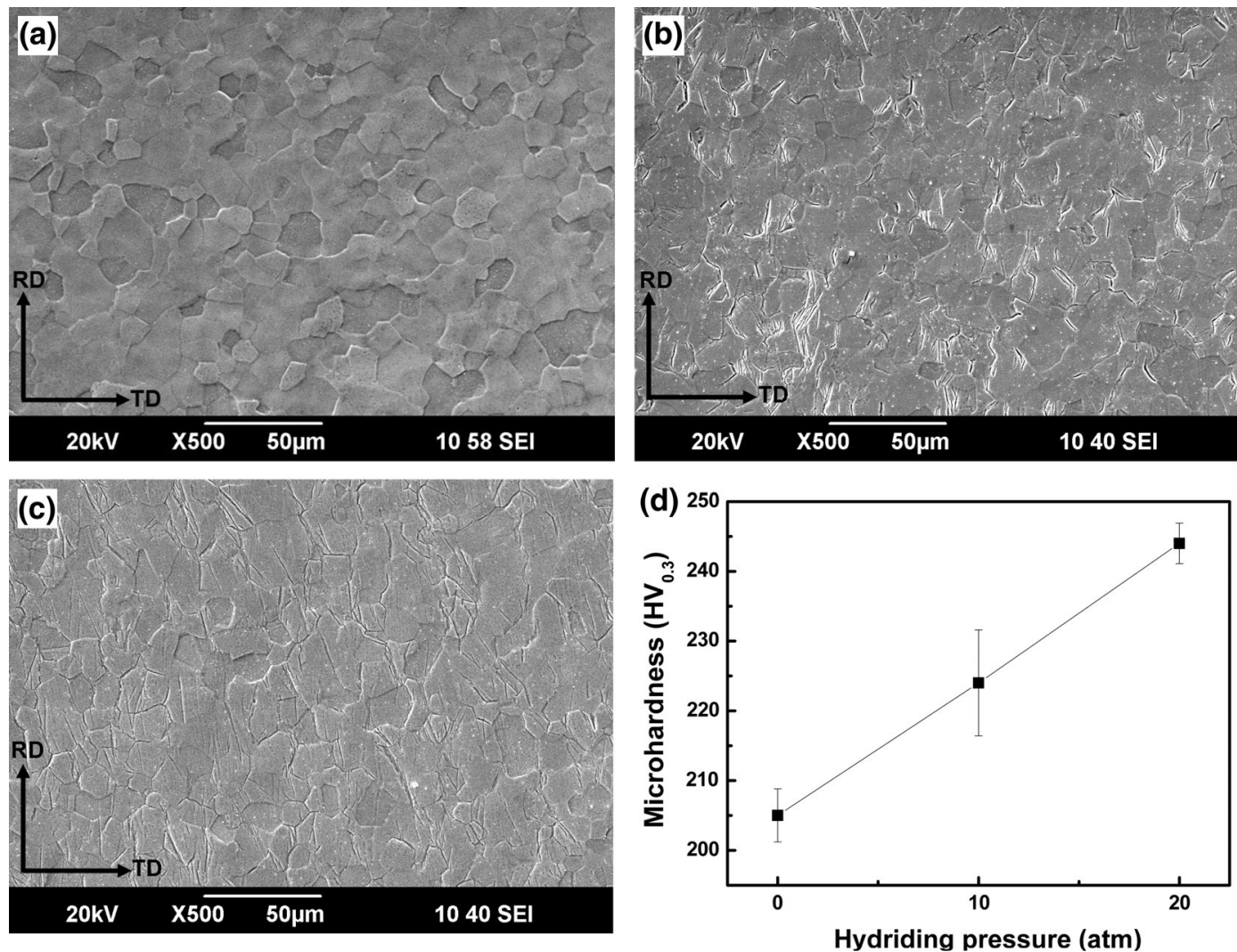

Fig. 3-SEM images showing typical microstructures on the etched RD-TD (rolling direction-transverse direction) sections of (a) the Zr-4 matrix and the hydrided samples at hydrogen pressures of $(b) 10 \mathrm{~atm}$ and (c) $20 \mathrm{~atm}$. (d) Variation of microhardness of the as-received samples before and after hydriding at various hydrogen pressures. Microhardness measurements are performed on the RD-TD sections, and error bars in the microhardness data (d) show one standard deviation.

The microstructure on the RD-TD section of the 20atm-hydrided plate was further characterized by EBSD. The indexing of the Kikuchi patterns recorded during the measurement confirms the phase compositions of $\delta$ $\mathrm{ZrH}_{1.66}$ and $\alpha-\mathrm{Zr}$ in the 20 -atm-hydrided sample. The typical microstructure for this sample shown in Figure 4(a) clearly reveals the precipitation of inter and intragranular hydride platelets (the region marked in red color). Moreover, the crystallographic orientation relationship between the $\delta$-hydride precipitate and $\alpha-\mathrm{Zr}$ matrix was analyzed using the pole figure method. ${ }^{[1]}$ As representatively illustrated in Figure 4(b), both intergranular (location "a" in Figure 4(a)) and intragranular (location "c" in Figure 4(a)) hydrides were found following the $\{111\}_{\delta \text {-ZrH1.66 }} / /(0001)_{\alpha-\mathrm{Zr}}$ with the surrounding $\alpha$-Zr matrix. This hydride-matrix correlation was also reported in Zricaloy-2 ${ }^{[22,23]}$ and $\mathrm{Zr}-2.5 \mathrm{Nb}^{[24]}$ alloys. The prevalence of this crystallographic relation essentially results from the preferred lattice matching of the involved $(0001)_{\alpha-\mathrm{Zr}}$ and $\{111\}_{\delta-\mathrm{ZrH1} .66}$ atomic planes ${ }^{[25]}$ which may contribute to minimize the strain energy associated with the hydride formation in the matrix. Additionally, a local misorientation map corresponding to the microstructure shown in Figure 4(a) is presented in Figure 4(c). The local misorientation within individual grains or intragranular misorientation reflects the extent of the strain (elastic or plastic) in the grains. In conjunction with the EBSD phase map (Figure 4(a)), this local misorientation map visualizes the strain distribution in the $\alpha-\mathrm{Zr}$ and $\delta$-hydride phases on a microstructural level and clearly indicates the higher strain level in the $\delta$-hydride phase. This conclusion is further supported by the finding of the specific grain average misorientation (GAM) plot shown in Figure 4(d), which quantitatively reveals a higher development of GAM in the $\delta$-hydride phase. The observed substantial GAM or strain in $\delta-\mathrm{ZrH}_{1.66}$ is attributed to the accommodation of large dilatational misfit strain associated with the $\alpha-\mathrm{Zr}$ (hcp) $\rightarrow \delta-\mathrm{ZrH}_{1.66}$ (fcc) transformation through the elastic lattice distortion or the generation of misfit dislocations. ${ }^{[6]}$ During the hydride transition, it is speculated that the local misorientation is comprehensively developed in all hydride grains. In contrast, the local misorientation is generated only partially in some limited $\alpha-\mathrm{Zr}$ grains adjacent to hydrides. Thus, a much more significant development of GAM in hydrides was found compared with the $\alpha-\mathrm{Zr}$ matrix (Figure 4(d)). This analysis concerning the GAM partition in different phases is evidenced by the transmission electron microscopy (TEM) investigation by Bai et al. ${ }^{[26]}$ suggesting a much higher dislocation density inside hydrides than the surrounding matrix.

The typical microtextures for the $\alpha-\mathrm{Zr}$ and $\delta-\mathrm{ZrH}_{1.66}$ phases in the 20-atm-hydrided sample, obtained from the EBSD measurement, are shown in Figure 5. As depicted in Figure 5(a), the $\alpha$ - $\mathrm{Zr}$ texture presents a 

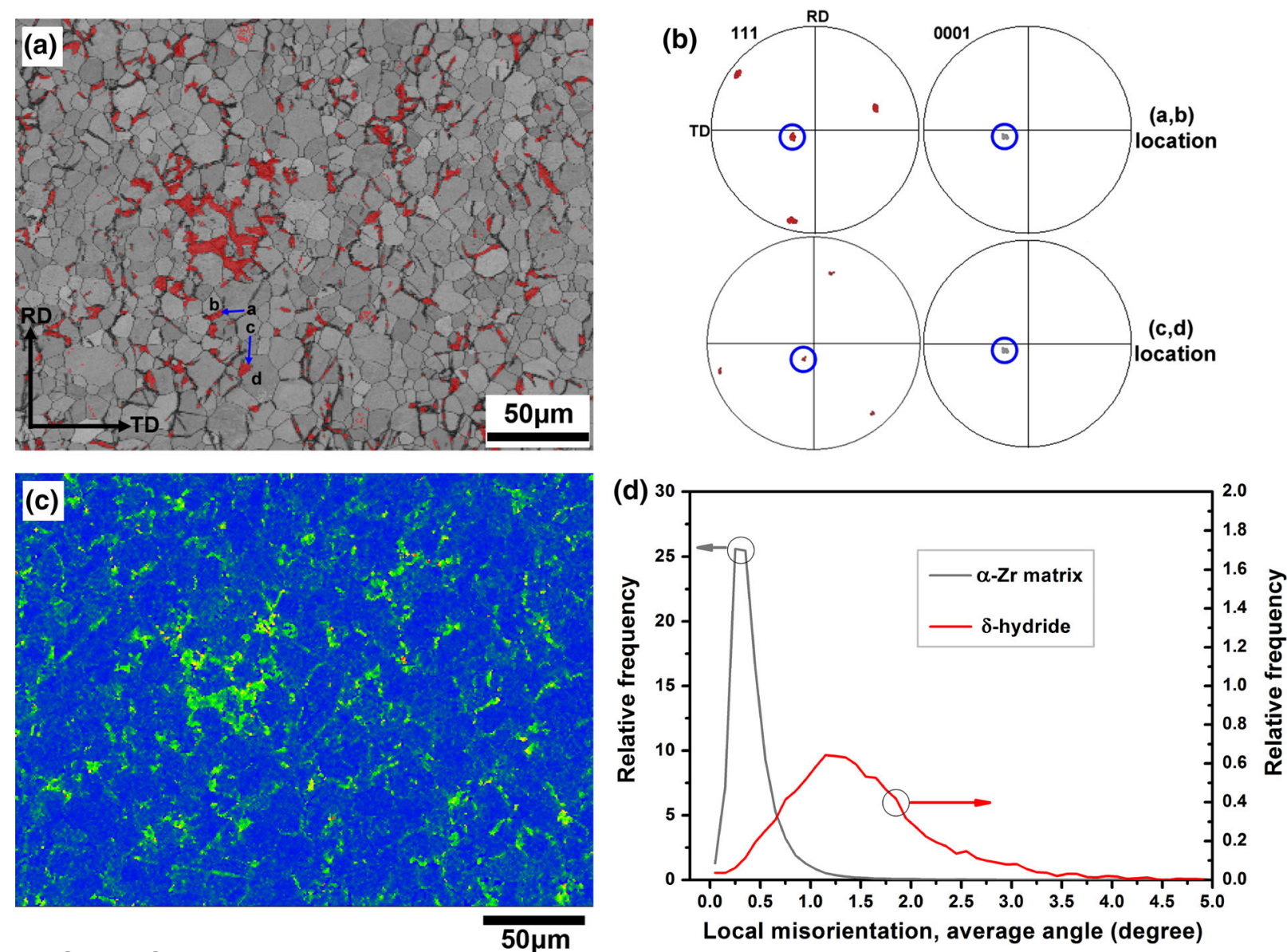

color scale

$50 \mu \mathrm{m}$

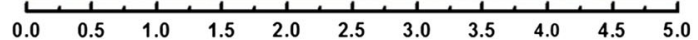

Fig. 4-EBSD experimental results of the 20-atm-hydrided sample: (a) EBSD phase map showing the presence of inter and intragranular hydrides (marked with red color); $(b)$ pole figure analysis illustrating the orientation relationship between $\delta$ - $\mathrm{ZrH}_{1.66}$ precipitate and $\alpha$ - $\mathrm{Zr}$ matrix; (c) local misorientation map and $(d)$ the corresponding grain average misorientation distributions in the $\alpha-\mathrm{Zr}$ and $\delta$ - $\mathrm{ZrH} \mathrm{H}_{1.66} \mathrm{phase}$

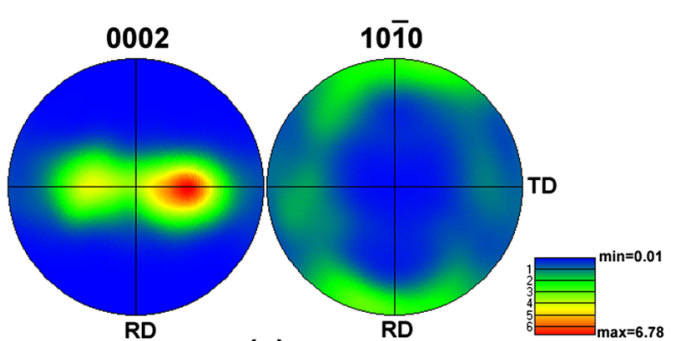

(a)

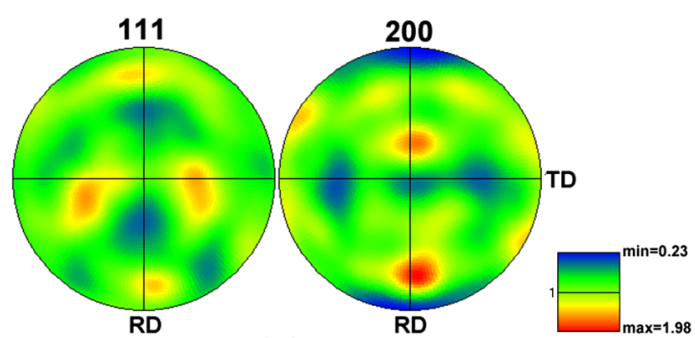

(b)

Fig. 5- (a) (0002) and (1010) pole figures of the $\alpha$ - Zr phase and (b) (111) and (200) pole figures of the $\delta$-ZrH $\mathrm{Zr}_{1.66}$ phase determined by EBSD for the 20 -atm-hydrided plate.

dominant feature of the double (0002) basal poles with two maxima titled about \pm 30 deg from ND toward TD along the ND-TD plane of the plate and moreover, there is a prismatic (1010) pole maximum mainly around the RD of the plate. Compared with the relatively strong $\alpha-\mathrm{Zr}$ texture characterized by a pole figure maximum of 6.78 multiples of the random distribution (m.r.d.), the $\delta$-hydride shows a weak texture featured by a pole maximum of 1.98 m.r.d. (appeared in the (200) pole figure (Figure 5(b)). Besides, it is interesting to find that the maxima of the $\alpha-\mathrm{Zr}$ basal pole and the $\delta-\mathrm{ZrH}_{1.66}$ (111) pole are almost at the same locations in their pole figures (Figure 5). This suggests that the $\{111\}$ lattice planes of $\delta-\mathrm{ZrH}_{1.66}$ predominately tend to orient parallel to the (0002) basal plane of the matrix, which is in line with 


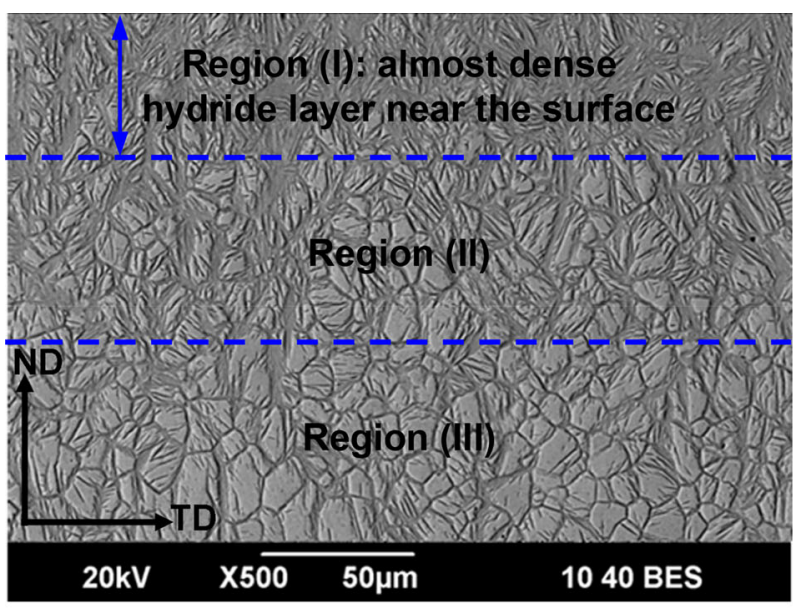

(a)

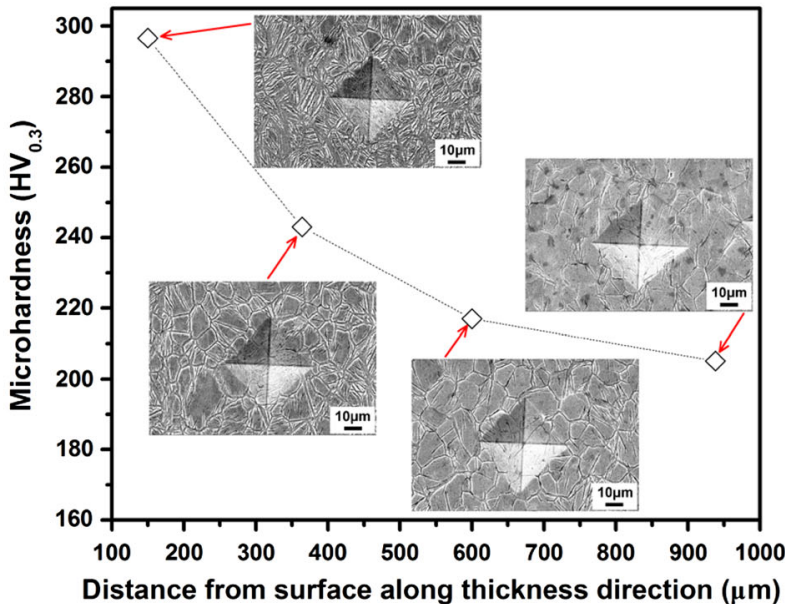

(b)

Fig. 6- (a) SEM image of the 20-atm-hydrided sample showing the hydride morphology and distribution on its ND-TD (normal directiontransverse direction) section; (b) Vickers microhardness of the 20-atm-hydrided sample as a function of the distance from the sample surface along the thickness direction (normal direction). SEM micrographs are included as insets in (b) showing the corresponding microstructures and indentation morphologies.
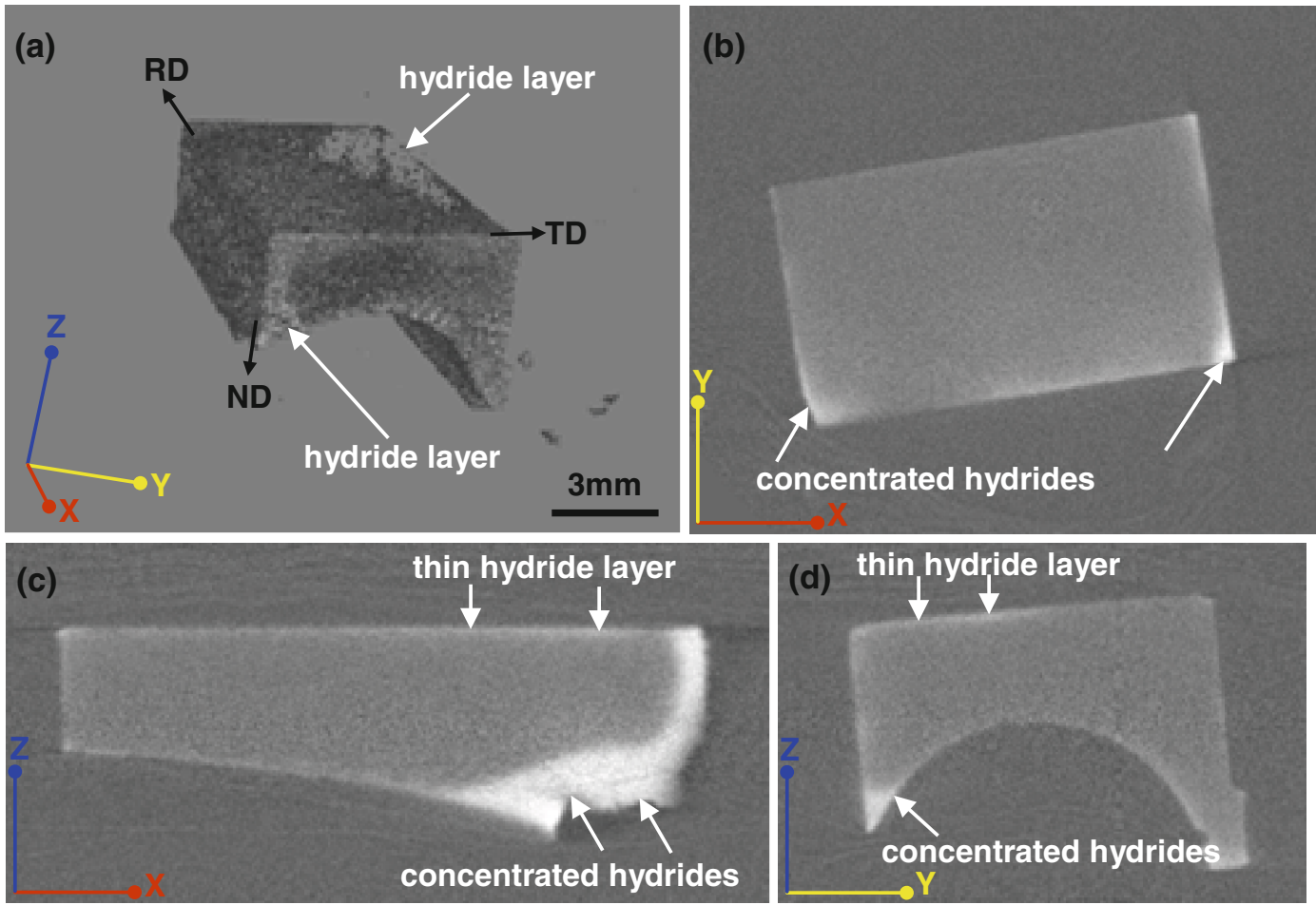

Fig. 7- (a) A tomographic reconstruction of the hydrided sample under a hydrogen pressure of $20 \mathrm{~atm}$. The coordinate systems for the real sample (RD-TD-ND) and the slicing of the reconstructed volume (X-Y-Z) are both marked. (b) XY slice, $(c)$ XY slice, and (d) YZ slice images showing the nonuniform hydride distribution in the sample.

the current finding based on Figure $4(\mathrm{~b})$ and the previous report. $^{[1]}$

The hydride morphology and distribution on the ND-TD (normal direction-transverse direction) section of the 20-atm-hydrided sample was also examined, as shown in Figure 6(a). There is an apparent hydride concentration gradient along the thickness direction (ND), and three regions with morphological differences are observed, i.e., Region (I): near the sample surface, hydrides locally concentrate and form the almost dense hydride layer; Region (II): below the dense hydride layer, the hydride volume fraction decreases progressively; and Region (III): far away from the surface, lessconcentrated hydrides exhibiting a relatively uniform distribution in the $\mathrm{Zr}-4$ matrix. It is well known that a nearly dense hydride layer (called hydride rim) usually appears near the outer surface of the zirconium alloy cladding materials in the reactor service conditions, 
mainly owing to the radial temperature gradient present during the operation. ${ }^{[27,28]}$ This hydride layer was also observed in previous studies ${ }^{[13,27,29]}$ and the current study (Figure 6(a)) under the artificial gaseous hydriding conditions. However, in the current hydriding conditions [soaked at $723 \mathrm{~K}\left(450{ }^{\circ} \mathrm{C}\right)$ for 5 hours in each thermal cycle], no significant temperature gradient could be present in the hydrided sample, given the fact that the sample size is in the order of millimeters. On the other hand, it is speculated that hydrides will first form at the surface region naturally because the solid solubility limit of hydrogen (i.e., the hydrogen saturation) will be reached there first. In addition, the effective hydrogen diffusion coefficient in the highly hydrided zone should be smaller than that in the region with lower hydride density, resulting in a blocking effect for hydrogen ingress into the bulk of the sample and the attendant preferential hydride accumulation near the surface. Figure 6(b) further depicts the microhardness profile measured along the thickness direction (ND) on the ND-TD section of the sample hydrided at $20 \mathrm{~atm}$. This reveals that, in conjunction with the SEM studies on microstructural features of the indentation morphology and hydride distribution at the various positions (insets in Figure 6(b)), there is a strong correlation between the microhardness and hydride volume fraction. At the position ( $~ 938 \mu \mathrm{m}$ from the surface) with low hydride content, the microhardness of $205 \mathrm{HV}_{0.3}$ was measured, whereas the highly concentrated hydrides near the sample surface (at a distance of $\sim 150 \mu \mathrm{m}$ from the surface) resulted in the microhardness as high as 297 $\mathrm{HV}_{0.3}$. As indicated by the microstructures of indentations (insets in Figure 6(b)), the accumulated hydrides enhanced the resistance to the local plastic deformation, thereby leading to the microhardness increase.

\section{Hydride Spatial Distribution Analysis}

Figure 7 presents the various views of the reconstructed 3D volume of the 20-atm-hydrided sample. Since hydrogen has a much higher neutron attenuation coefficient than that of zirconium, the areas of higher attenuation shown as lighter gray in the reconstructed grayscale images indicate the presence of hydrides. The presence of an inhomogeneous spatial distribution of hydrides could be clearly identified from these tomographic images. Thin hydride layers were directly observed on the sample surfaces, which further verified the fact that some hydride layers appeared on the surface as previously implied by the sectional microstructural examination (Figure 6(a)). Besides the "surface effect" detected, it appears to be another "edge effect" for the hydride formation. Specifically, the concentrated hydrides precipitated at the edges (Figures 7(b) and (c)) and the sharp corner (Figure 7(d)) of the sample. It is considered that the likely occurrence of 3D diffusion of hydrogen at sample edges (two adjacent free surfaces) and the corner (three or more adjacent free surfaces) enhanced the hydrogen ingress into the sample and subsequently facilitated the formation of concentrated hydrides at these regions (Figures 7(b) through (d)).

\section{CONCLUSIONS}

The microscopic and macroscopic observations on the hydride precipitation and distribution behaviors in $\mathrm{Zr}-4$ plates were performed. The $\delta-\mathrm{ZrH}_{1.66}$ hydrides in the form of platelets (volume fraction $\sim 10 \mathrm{pct}$ ) were precipitated in the matrix when hydriding at a pressure of $20 \mathrm{~atm}$. Moreover, the orientation relationship between $\alpha-\mathrm{Zr}$ and $\delta$-hydride precipitate was $\{111\}_{\delta \text {-ZrH1.66 }} / /$ $(0001)_{\alpha-Z r}$. The metallographic examinations demonstrated that hydrides showed a relatively uniform distribution on the RD-TD section of the plate, while on the ND-TD section a hydride concentration gradient was present with a dense hydride layer near the surface demonstrating the corresponding highest microhardness of $297 \mathrm{HV}_{0.3}$. The macroscopic inspections using neutron tomography clearly revealed that there was a certain degree of inhomogeneity for the spatial distribution of hydrides. Thin hydride layers on the samples surface and concentrated hydrides at the edges/corner were observed. It is assumed that the formation of thin hydride layers on the sample surfaces (a so-called "surface effect") is mainly attributed to the preferential hydrogen saturation and accumulation near the sample surface. The 3D diffusion of hydrogen possibly occurred at the sample edges and the corner, thus enhancing the hydrogen uptake into the sample and further facilitating the precipitation of concentrated hydrides at the sample edges/corner regions (the so-called edge effect).

\section{ACKNOWLEDGMENTS}

The authors wish to thank Mr. Joel Davis from the Australian Nuclear Science and Technology Organisation (ANSTO) for his technical assistance with the EBSD experiment. One of the authors (Zhiyang Wang) gratefully appreciates the financial support from the China Scholarship Council (CSC) and ANSTO.

\section{REFERENCES}

1. N.A.P. Kiran Kumar, J.A. Szpunar, and Z. He: J. Nucl. Mater., 2010, vol. 403, pp. 101-7.

2. K.B. Colas, A.T. Motta, J.D. Almer, M.R. Daymond, M. Kerr, A.D. Banchik, P. Vizcaino, and J.R. Santisteban: Acta Mater., 2010, vol. 58, pp. 6575-83.

3. K. Nuttall, D.P. McCooeye, A.J. Rogowski, and F. Havelock: Scripta Metall., 1976, vol. 10, pp. 979-82.

4. M. Veleva, S. Arsene, M.-C. Record, J. Bechade, and J.B. Bai: Metall. Mater. Trans. A, 2003, vol. 34A, pp. 567-78.

5. K.V. Mani Krishna, A. Sain, I. Samajdar, G.K. Dey, D. Srivastava, S. Neogy, R. Tewari, and S. Banerjee: Acta Mater., 2006, vol. 54, pp. 4665-75.

6. J.B. Bai, C. Prioul, and D. François: Metall. Mater. Trans. A, 1994, vol. 25A, pp. 1185-97.

7. M. Kerr, M.R. Daymond, R.A. Holt, J.D. Almer, S. Stafford, and K.B. Colas: Scripta Mater., 2009, vol. 61, pp. 939-42.

8. A. Agrawal, Y. Kashyap, P.S. Sarkar, A.N. Behra, M. Shukla, R.N. Singh, A. Sinha, and J.K. Chakravartty: J. Nucl. Mater., 2012, vol. 421, pp. 47-53.

9. R. Yasuda, M. Nakata, M. Matsubayashi, K. Harada, Y. Hatakeyama, and H. Amano: J. Nucl. Mater., 2003, vol. 320, pp. 223-30. 
10. M. Grosse, G. Kuehne, M. Steinbrueck, E. Lehmann, J. Stuckert, and P. Vontobel: J. Phys. Condens. Matter, 2008, vol. 20, pp. 104263-71.

11. M. Grosse, J. Stuckert, M. Steinbrück, and A. Kaestner: J. Nucl. Mater., 2012, vol. 420, pp. 575-82.

12. A.P. Kaestner, S. Hartmann, G. Kühne, G. Frei, C. Grünzweig, L. Josic, F. Schmid, and E.H. Lehmann: Nucl. Instr. Method A, 2011, vol. 659, pp. 387-93

13. R.S. Daum, Y.S. Chu, and A.T. Motta: J. Nucl. Mater., 2009, vol. 392, pp. 453-63.

14. Y Zhou and GH Wu: Analysis Methods in Materials Scinece$X$-Ray Diffraction and Electron Microscopy, 2nd ed., Harbin Institute of Technology Press, Harbin, 2007, p. 48.

15. M. Birkholz: Thin Film Analysis by X-ray Scattering, Wiley-VCH, Weinheim, 2006, p. 59.

16. G.J.C. Carpenter: J. Nucl. Mater., 1973, vol. 48, pp. 264-66.

17. J.R. Santisteban, M.A. Vicente-Alvarez, P. Vizcaíno, A.D. Banchik, and J.D. Almer: Acta Mater., 2010, vol. 58, pp. 6609-18.

18. S. Oh, C. Jang, J.H. Kim, and Y.H. Jeong: Mater. Sci. Eng. A, 2010, vol. 527, pp. 1306-13.
19. Z.Y. Wang, H.J. Li, U. Garbe, M.D. Callaghan, Y.B. Wang, and X.Z. Liao: Mater. Lett., 2012, vol. 68, pp. 310-3.

20. Z.Y. Wang, U. Garbe, H.J. Li, A.J. Studer, R.P. Harrison, M.D. Callaghan, Y.B. Wang, and X.Z. Liao: Scripta Mater., 2012, vol. 67, pp. 752-5.

21. S. Arsene, J.B. Bai, and P. Bompard: Metall. Mater. Trans. A, 2003, vol. 34A, pp. 579-88.

22. K. Une and S. Ishimoto: J. Nucl. Mater., 2006, vol. 357, pp. 147-55.

23. K. Une and S. Ishimoto: J. Nucl. Mater., 2009, vol. 389, pp. 436-42.

24. K.V. Mani Krishna, D. Srivastava, G.K. Dey, V. Hiwarkar, I. Samajdar, and S. Banerjee: J. Nucl. Mater., 2011, vol. 414, pp. 270-75.

25. W. Qin, N.A.P. Kiran Kumar, J.A. Szpunar, and J. Kozinski: Acta Mater., 2011, vol. 59, pp. 7010-21.

26. J.B. Bai, N. Ji, D. Gilbon, C. Prioul, and D. François: Metall. Mater. Trans. A, 1994, vol. 25A, pp. 1199-208.

27. N. Fumihisa: J. Nucl. Mater., 2011, vol. 415, pp. 117-22.

28. A.T. Motta and L.Q. Chen: J. Met., 2012, vol. 64, pp. 1403-08.

29. J.L. Sacedón, M. Diaz, J.S. Moya, B. RemartInez, and J. Izquierdo: J.Nucl.Mater., 2004, vol.327, pp. 11-18. 